\title{
STUDY ON STRIKING SHIP WITH LOADING IMPACT ON THE PERFORMANCE OF THE DOUBLE HULL OIL TANKER COLLISION
}

\author{
Wenfeng Wu, Ph. D. \\ Yubin Yang, M. S. \\ Jianwei Zhang, Ph. D. \\ Jinshu Lu, Ph. D. \\ School of Port and Transportation Engineering, Zhejiang Ocean University, Zhoushan, Zhejiang, China
}

\begin{abstract}
Due to the great danger of the collision of oil tankers, lots of research on the collision of oil tankers has been carried out. But, at present, the research on the collision of oil tankers mainly focuses on the loading condition of the struck ship, ignores the impact on the loading condition of the striking ship. However, during the actual oil tanker collision, the striking ship is generally in the state of loading. Therefore, it is necessary to carry out the analysis of the impact of the loading condition of the striking ship on the collision damage of the oil tanker. In this paper, the effect of striking ship with loading on the impact performance of the side structure during the collision of the cargo double hull oil tanker has been investigated. The ship collision model was established by using the finite element software ANSYS/ LS-DYNA which is based on 7000 tons of double hull oil tankers. Based on the analysis of the collision force, impact of striking speed changes, impact of striking deep changes and structural energy absorption during the collision process, the influence of the striking ship with loading on the damage mechanism and the impact performance of the double shell oil ship side structure was expounded. The results show that the influence of the striking ship with loading can be great to the damage to side hull during the research of the collision performance of the oil tanker.
\end{abstract}

Keywords: Ship collision; Fluid-structure interaction; Impact parameters; Numerical simulation

\section{INTRODUCTION}

With the rapid development of the world economy, the maritime trade has become more and more busy, prompting a surge in the number of navigating ships, the increasing speed of ships and the more crowded route, which makes the probability of collisions between ships. As a complex and huge offshore movable building, the consequences of a collision are often catastrophic. Especially, the collision of a large oil tanker can not only cause damage to the hull structure, but also cause severe economic loss and potential environmental damage $[1,2]$. Therefore, it is of great significance to carry out the research on the collision performance of the oil tanker, which is for the safety of navigation and the protection of the environment.

In the past, due to the complexity of the collision problem of oil tankers and the limitations of technical solutions, the research on the structural crash performance of oil tankers generally focused on the plastic deformation and failure mechanisms of the structures, ignored the influence of liquid cargo $[3,4,5,6,7,8]$. Recently, with the in-depth study of the mechanism of collision damage and the development of calculation power and sophistication of the software, some scholars have discussed the collision of oil tankers under the condition of loading.

Recently, the researches on the collision problem of liquid cargo tanker mainly focus on the sloshing interaction in ship collisions and the research object is mainly struck ship. Zhang [9] used three kinds of numerical simulation methods to study the interaction between fluid and structure of an oil tanker under impact load. The results show that the Lagrange Euler method is reasonable. It has a lower computational cost and can be used as a practical engineering appilication. Cui [10] analyzed the impact of liquid cargo on the anti-impact performance of the side structures and found that the liquid cargo had some influence on the side impact performance of the ship. Wu [11] analyzed the influence of tank sloshing on the crashworthiness of side structures of double-hull tankers with numerical software 
ANSYS /LS-DYNA. The results show that the impact of liquid cargo can not be ignored in the study of the collision of double hull tanker.

In addition, a preliminary study of the impact on striking ship with loading has been carried out. Tabri [12] studied the collision performance of ships under the influence of sloshing by model tests and found that the sloshing of fluid in partially filled tanks influenced the collision dynamics and lowered the energy available for structural deformations. Rudan [13] used the arbitrary Eulerian-Langrangian finite element method to analyze the sloshing interaction in ship collisions and found the free-surface elevation inside the partially filled tanks was well predicted with the numerical approach. However, none of these studies have deeply analyzed the mechanism of liquid sloshing on structural damage.

The aim of this paper is to investigate the impact of liquid cargo impact on the collision damage characteristics of double hull tankers. In order to get more intuitive results, four groups are set as follow: striking ship no load, striking ship single cabin loading with $80 \%$ of high-filling level, striking ship double cabin loading with $80 \%$ of high-filling level, striking ship triple cabin loading with $80 \%$ of high-filling level. Numerical simulations of a collision between two identical double-hull tankers are carried out by using the finite element software ANSYS/LS-DYNA. Through the comparative analysis of collision force and structural damage and deformation, the general rule of impact on the collision damage characteristics of double hull tankers with liquid cargo is obtained.

\section{COLLISION SCENARIO}

In this paper, a 7,000DWT double-hull tanker is selected as the research object. The striking ship is vertically centered at $4 \mathrm{~m} / \mathrm{s}$ and hit a stationary double hull tanker. The main dimension of the collision ships are presented on Tab. 1 .

Tab. 1. Main dimensions of collision ships

\begin{tabular}{|c|c|c|c|}
\hline \multicolumn{2}{|c|}{ Struck ship } & \multicolumn{2}{c|}{ Striking ship } \\
\hline Item & Value & Item & Value \\
\hline $\begin{array}{c}\text { Spacing between } \\
\text { transverse web } \\
\text { frames }\end{array}$ & $2.6 \mathrm{~m}$ & $\begin{array}{c}\text { The height } \\
\text { from bulb } \\
\text { bow to baseline }\end{array}$ & $6.3 \mathrm{~m}$ \\
\hline $\begin{array}{c}\text { Spacing between } \\
\text { longitudinal } \\
\text { girders }\end{array}$ & $2.6 \mathrm{~m}$ & $\begin{array}{c}\text { The length of } \\
\text { bulb bow }\end{array}$ & $3.07 \mathrm{~m}$ \\
\hline \begin{tabular}{c} 
Plate thickness \\
\hline
\end{tabular} & $0.016 \mathrm{~m}$ & & \\
\hline
\end{tabular}

In addition, in order to explore the impact characteristics of striking ship with loading on the collision damage of doublehull tankers, the loading conditions of the impact ship are four different states: no-load, single-cabin load, double-cabin load and three-cabin load. Ships collision scheme is shown in Tab. 2. the struck ship cabin distribution is shown in Fig. 1.
Tab. 2. Ship collision scheme

\begin{tabular}{|c|c|c|}
\hline Group & Tonnage & $\begin{array}{l}\text { Impact ship loaded } \\
\text { condition }\end{array}$ \\
\hline $\begin{array}{l}\text { Case } 1 \\
\text { (No load) }\end{array}$ & \multirow{4}{*}{ 7000DWT } & No liquid cargo loading \\
\hline $\begin{array}{c}\text { Case } 2 \\
\text { (Single cabin loading) }\end{array}$ & & $\begin{array}{c}\text { First cabin loading } \\
\text { liquid cargo }\end{array}$ \\
\hline $\begin{array}{c}\text { Case } 3 \\
\text { (Double cabin loading) }\end{array}$ & & $\begin{array}{l}\text { First cabin and second } \\
\text { cabin loading liquid } \\
\text { cargo }\end{array}$ \\
\hline $\begin{array}{c}\text { Case } 4 \\
\text { (Triple cabin loading) }\end{array}$ & & $\begin{array}{c}\text { Three cabin loading } \\
\text { liquid cargo }\end{array}$ \\
\hline
\end{tabular}

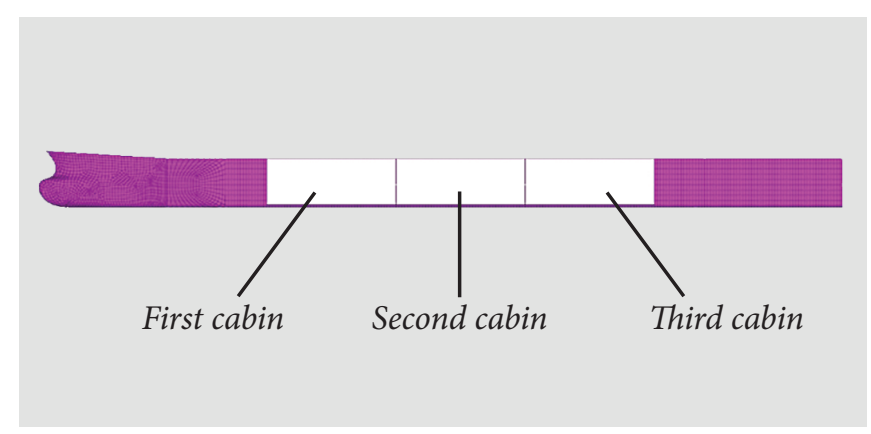

Fig. 1. Cabin distribution of struck ship

\section{MODEL ESTABLISHMENT}

\section{SHIP COLLISION MODEL}

Taking into account the partial characteristics of the ship collision and the computational efficiency calculation, the model is simplified in the process of establishing the ship model [14]. In this case, the struck ship is simplified into a cargo hold, and the center of the ship is guaranteed to be the center of mass and the center of gravity. The structure of the bow of the striking ship is consistent with the shape of the prototype bow and only the tank shell is retained in the side tank structure, but the centroid and weight of the striking ship are to be consistent with those of the actual ship. Ship collision numerical model is shown in Fig. 2.

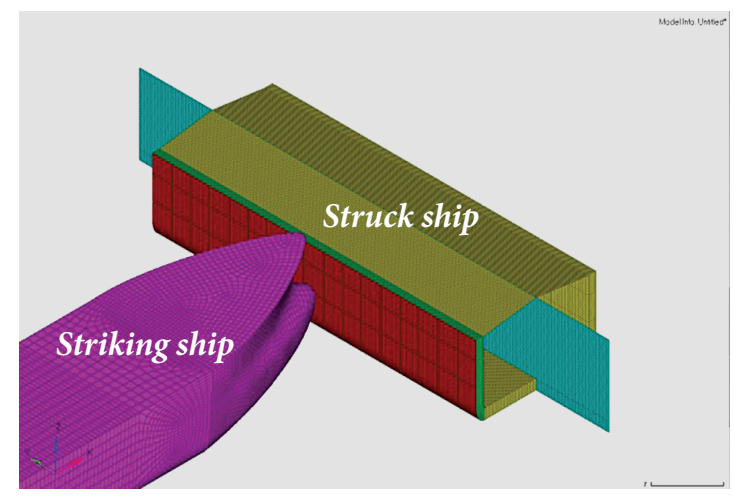

Fig. 2. Ship collision numerical model 
In the collision of ships, the stiffness of the striking ship's bow is generally much higher than the side structure of the struck ship. Therefore, in this paper, a rigid material is used in the striking ship, and a plastic kinematics model is used in the struck ship. The parameters set in Tab. 3. Furthermore, the structure of collision ships are modeled with Belytschko-Tsay shell elements [15]. The contact between the striking ship and the struck ship is implemented by using a contact-automaticto-surface formulation.

Tab. 3. Plastic kinematics material properties

\begin{tabular}{|c|c|}
\hline Material properties & Value \\
\hline Density & $7800 \mathrm{~kg} / \mathrm{m}^{3}$ \\
\hline Young's modulus & $2.1 \times 10^{11} \mathrm{~N} / \mathrm{m}^{2}$ \\
\hline Poisson's ratio & 0.3 \\
\hline Tangent modulus & $1.18 \times 10^{9} \mathrm{~N} / \mathrm{m}^{2}$ \\
\hline Yield stress & $2.35 \times 10^{8} \mathrm{~N} / \mathrm{m}^{2}$ \\
\hline Hardening parameter & 0 \\
\hline Strain rate parameter(P) & 5 \\
\hline Strain rate parameter(C) & 40.4 \\
\hline Failure strain & 0.15 \\
\hline
\end{tabular}

\section{CABIN CRUDE MODEL}

Cabin crude oil model includes two parts, crude oil and air. The air and crude oil are modeled by using the eight-node solid elements. The model of crude oil in the cabin is shown in Fig. 3. In order to realize the fluid-structure interaction, the Arbitrary Lagrangian-Eulerian (ALE) algorithm is adopted. The interaction between the structure and the crude oil is defined by using the LS-DYNA coupling command "Constrained Lagrange in Solid" [16]. Besides, the material properties of the fluid model in this paper are mainly described by the NULL material model and the equation of state (EOS) in LS-DYNA.

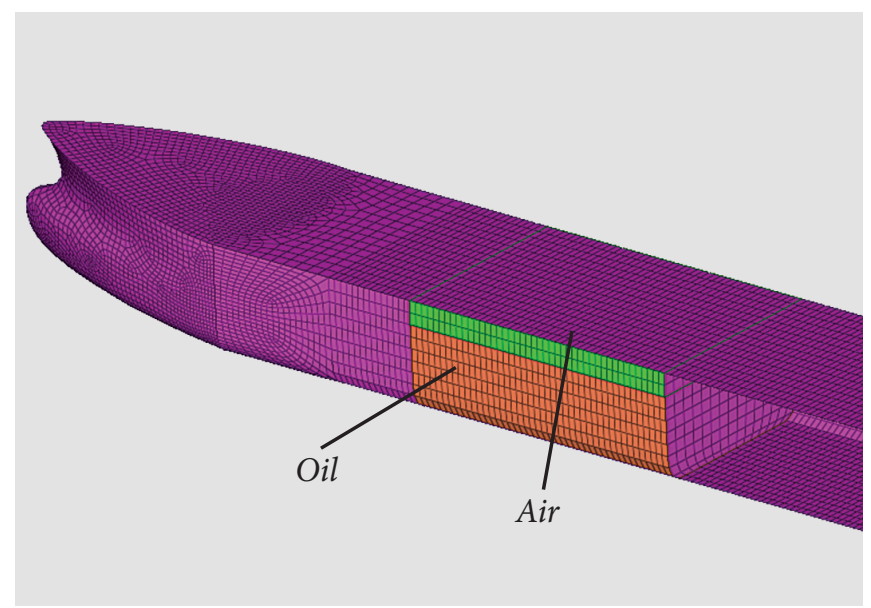

Fig. 3. Crude oil model
For air, the equation of state uses the linear polynomial equation of state provided by LS-DYNA and is described by the keyword "EOS LINEAR POLYNOMIAL". Air material parameters are listed in Tab. 4. The equation of state defines the pressure of the compressed material is shown in Eq. (1).

$$
P=C_{0}+C_{1} \mu+C_{2} \mu^{2}+C_{3} \mu^{3}+\left(C_{4}+C_{5} \mu+C_{6} \mu^{2}\right) E
$$

In Eq. (1):

$P \quad$ - Pressure;

$C_{0}, C_{1}, C_{2}, C_{3}, C_{4}, C_{5}$ and $C_{6}-$ Custom constants;

$\mu \quad$ - The volume change rate;

$E \quad-$ The internal energy per initial volume.

Tab. 4. Air material parameters

\begin{tabular}{|c|c|}
\hline Material properties & Value \\
\hline Density & $1.29 \mathrm{~kg} / \mathrm{m}^{3}$ \\
\hline Constant $\left(\mathrm{C}_{0}-\mathrm{C}_{3}\right)$ & 0 \\
\hline Constant $\left(\mathrm{C}_{4}, \mathrm{C}_{5}\right)$ & 0.4 \\
\hline Constant $\left(\mathrm{C}_{6}\right)$ & 0 \\
\hline
\end{tabular}

For crude oil, the equation of state uses the Gruneusen equation provided in LS-DYNA and is described by the keyword "EOS GRUNEUSEN". Crude material parameters are given in Tab. 5. The equation of state defines the pressure of the compressed material as shown in Eq. (2).

$$
P=\frac{\rho_{0} C^{2} \mu\left[1+\left(1-\frac{\gamma_{0}}{2}\right) \mu\right]}{\left[1-\left(S_{1}-1\right) \mu-S_{2} \frac{\mu^{2}}{\mu+1}-S_{3} \frac{\mu^{3}}{(\mu+1)^{2}}\right]^{2}}+\left(\gamma_{0}+\alpha \mu\right) E
$$

In Eq. (2):

$P$ - Pressure;

$\rho_{0} \quad$ The initial fluid density;

$C$ - The intercept of $v_{s}-v_{p}$ curve;

$\rho$ - The density of the fluid;

$\mu \quad$ - The specific volume, $\mu=\rho / \rho_{0}-1$;

$\gamma_{0} \quad$ - The Gruneisen gamma;

$S_{1}, S_{2}, S_{3} \quad$ The coefficients of the slope of the $v_{s}-v_{p}$ curve;

$E \quad-$ The internal energy per initial volume.

Tab. 5. Crude oil material parameters

\begin{tabular}{|c|c|}
\hline Material properties & Value \\
\hline Density & $0.855 \times 10^{3} \mathrm{~kg} / \mathrm{m}^{3}$ \\
\hline Curve intercept (C) & $1.5 \times 10^{3}$ \\
\hline Kinematic viscosity & $1.019 \times 10^{-5} \mathrm{~m}^{2} / \mathrm{S}$ \\
\hline Slope coefficient $\left(\mathrm{S}_{1}\right)$ & 1.921 \\
\hline Slope coefficient $\left(\mathrm{S}_{2}\right)$ & -0.096 \\
\hline Gruneisen gamma & 0.5 \\
\hline
\end{tabular}




\section{SIMULATION RESULTS AND ANALYSIS}

\section{ANALYSIS OF THE SPEED \\ CHANGE OF COLLISION SHIP}

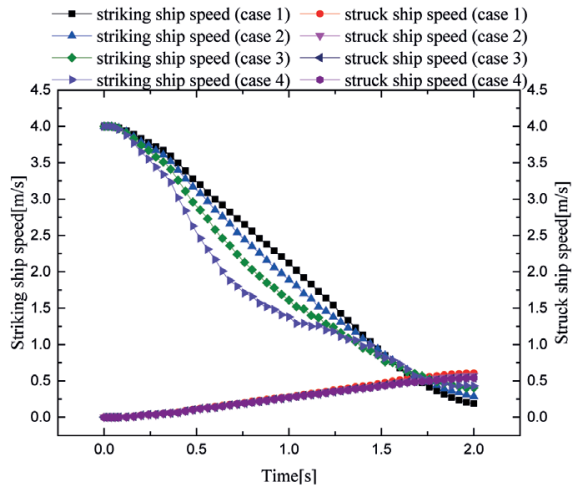

Fig. 4. Ship speed versus time for different loading of the striking ship

Fig. 4. is the curve for collision ships speed versus time for different loading of the striking ship. As shown in the figure, the speed of the collision ships includes the striking ship speed and the struck ship speed. It can be seen from the figure that the trend of the struck speed of each model is basically consistent with time.

The speed changes of the striking ship are mainly divided into three stages: the first stage of the impact time is $0.38 \mathrm{~s}$ ago, the striking ship is in contact with the struck ship in this stage. The speed variation of the striking ship is not quite different because of the lack of timely response of the liquid cargo and the similar collision situation in the initial collision ship. The second stage of the impact time is about $0.38 \mathrm{~s}$ to $1.7 \mathrm{~s}$, through the postprocessing software, it is found that the fluid in the cabin begin to respond at this time. It can be seen that the liquid cargo starts to respond at the time. The specific response is reflected in the more impact cargo, the faster the speed of impact ship changes. The main reason of this response is the impact of liquid cargo sloshing. In the third stage, the impact time is about after $1.7 \mathrm{~s}$, the drift speed of the struck ship is greater than the speed of the striking ship, and the interaction between the striking ship and the struck ship is weakened.

\section{PENETRATION DEPTH CHANGE ANALYSIS}

Fig. 5. is the collision ship penetration depth versus time curve. As can be seen from Fig. 5., the penetration depth changes are mainly divided into three stages.

In the first stage, the impact time is about $0.38 \mathrm{~s}$ ago. During this phase, the striking ship's bulb bow contacts the side structure of the struck ship but do not crash the inner shell of the struck ship. The collision energy is transferred to the struck ship through the side structure deformation. In this case, due to the short collision time, there is no obvious response to the liquid cargo in the striking ship. In addition, the quality and structure of the collision are consistent, so the penetration depth is basically consistant with the time changes. The second phase of the impact time is about $0.38 \mathrm{~s}$ to $1.7 \mathrm{~s}$, as time increase, the more liquid

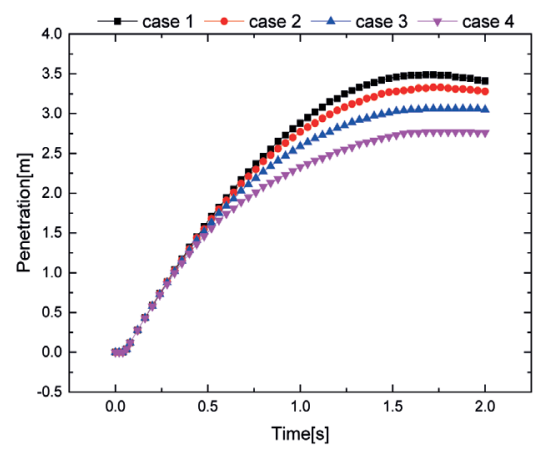

Fig. 5. Penetration versus time for different loading of the striking ship

cargo the striking ship carries, the shallower the penetration depth is. It is mainly due to the collision energy produced by the striking ship partially absorbed by the sloshing of liquid cargo in the cabin resulting from the sudden drop in impact speed of the striking ship. The third stage is after $1.7 \mathrm{~s}$, the penetration depth changes very slowly and has a downward trend. At this stage, the collision speed of the struck ship is faster than the speed of the striking ship, the interaction between the striking ship and the struck ship is weakened. The striking ship and the struck ship slowly are separated at this stage.

\section{COLLISION FORCE ANALYSIS}

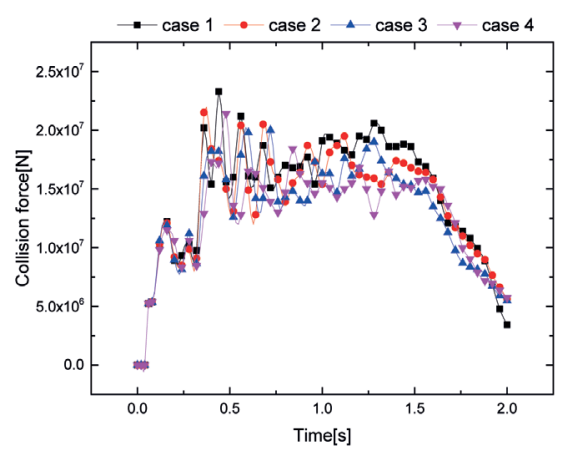

Fig. 6. Collision force versus time for different loading of the striking ship

Fig. 6. shows the curve for collision force versus time with different loading of the striking ship. As shown in the figure, the model collision force can be divided into three stages.

The first stage of collision time is about $0.38 \mathrm{~s}$ ago, the striking ship impacts the struck ship, but this collision is not the role of the inner shell. This stage is $0.17 \mathrm{~s}$ ago, the collision force is significantly increased due to the deformation of the side structure of the ship being struck against the propulsion of the striking ship. In the period of $0.17 \mathrm{~s}$ to $0.38 \mathrm{~s}$, due to the rupture of the struck ship's out shell, the striking ship has a direct contact with the longitudinal girders and transverse web frames but has not yet directly interacted with the inner shell. Because of the weak response of liquid cargo in striking ship cabin at this stage and the impact conditions in each collision scene are the same, the collision force of each model in this stage is basically the same.

The second stage of collision time is about $0.38 \mathrm{~s}$ to $1.7 \mathrm{~s}$, due to the striking ship contact with the inner shell of the struck ship, the collision force rises rapidly until the inner shell 
is damaged, then the collision force decreases. Besides, with the continued impact of the striking ship, there is a certain fluctuation in the collision force.

In the third stage, when the collision time reaches to $1.7 \mathrm{~s}$, the collision force begins to drop. At this time, the collision between the striking ship and the struck ship are weakened because the striking ship speed is less than the speed of the struck ship. Due to the complexity of the collision process at this stage, the impact on the striking ship with loading does not have a significant effect on the impact.

\section{ENERGY ABSORPTION ANALYSIS}

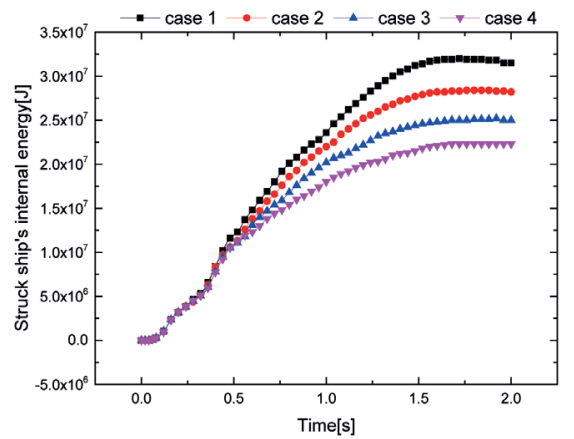

Fig. 7. Struck ship's internal energy versus time for different loading of the striking ship

Fig. 7. shows the internal energy of the struck ship varies with time. It can be seen from the figure that in the initial stage of the collision, that is, before the collision time is about $0.38 \mathrm{~s}$, whether the striking ship laden with liquid cargo or not, it will have little effect on the internal energy change in the struck ship. At this moment, there is no obvious response to the liquid cargo in the striking ship's cabin, and the collision modes are basically the same. Therefore, the internal energy produced by the structural deformation of the struck ship during this stage is less related to the loading state of the striking ship. At the later stage of the collision, that is, after the collision time is about $0.38 \mathrm{~s}$, it can be seen from Fig. 4. that at this moment, due to the obvious response of liquid cargo, the collision speed of striking ship is obviously different to the striking ship under the loading condition. The more liquid cargo the striking ship loads, the faster the speed of striking ship decreases, the shallower the penetration depth is, which leads to a smaller internal energy of struck ship.

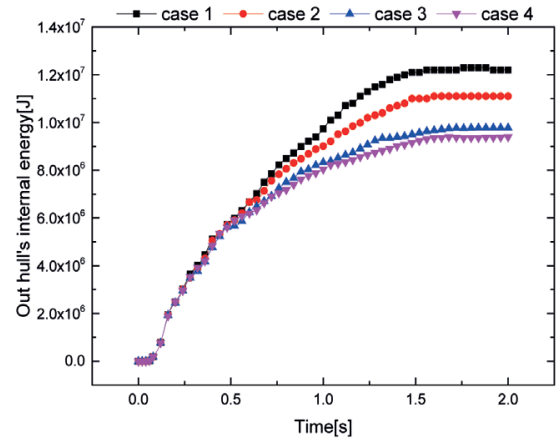

Fig. 8. Out hull's internal energy versus time for different loading of the striking ship
Fig. 8. reflects the out hull's internal energy of the struck ship versus time for four different loading of the striking ship. It can be seen from the figure that the changes of the out hull's internal energy of the four kinds of collision cases are basically the same before the collision time is about $0.38 \mathrm{~s}$. The main reason is that the liquid cargo in the cabin does not play a significant role in the beginning of the collision. After the collision time is about $0.38 \mathrm{~s}$, with the increase of the penetration depth, the shell continues to bend and deform in the direction of collision, out hull's internal energy increases gradually. As can be seen from Fig. 4., in the period of $0.38 \mathrm{~s}$ to $1.7 \mathrm{~s}$, the impact velocity decreases with the decrease of liquid cargo of the striking ship, and the degree of the deformation of the shell structure is relatively low. After $1.7 \mathrm{~s}$, due to the separation of the striking ship and the struck ship, the impact of the striking ship on the struck ship is rapidly reduced and the deformation energy is absorbed by the struck ship's side structure is basically completed. As a result, the internal energy of the out hull of the struck ship tends to be gentle.

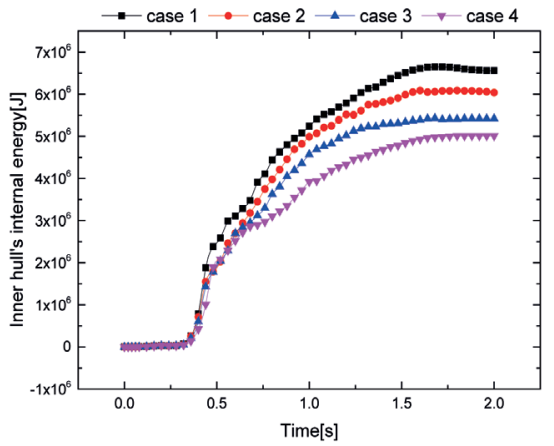

Fig. 9. Inner hull's internal energy versus time for different loading of the striking ship

Fig. 9. reflects the inner hull's internal energy of the struck ship versus time in different loading of the striking ship. It can be seen from the figure that before the time is about $0.38 \mathrm{~s}$, the striking ship does not have a significant effect on the inner shell, and the internal energy of inner shell increases gently. With the impelling of the collision time, the striking ship contacts with the inner shell, and the internal energy of inner shell increases rapidly. At this time, the internal energy of inner shell is mainly derived from the inner shell deformation caused by the collision. The more liquid cargo the striking ship loads, the more obvious speed the striking ship falls, the shallower the penetration depth is, the less energy the deformation of the inner shell absorbs, the lighter the ship will be. To sum up, during the collision of ships, the more the striking ship carries liquid cargo, the less the energy absorbed by the shell plates and the whole ship, which indicates that striking ship with loading has an important impact on the collision damage of the ships.

\section{CONCLUSION}

In this paper, taking the double-hull tankers as the research object, using the application of ANSYS / LS-DYNA to compare the impact of ship collision on the side shell of double hull oil tankers, the main conclusions are as follows: 
(1) In the early stage of collision, under the loading condition of the striking ship has little impact on penetration depth, collision force and structure energy absorption, etc. It can ignore the influence of side structure damage which is caused by the loading striking ship.

(2) In the later stage of collision, the collision of cargo loading striking ship has an obvious influence on the collision of double hull oil tankers, which is mainly reflected in the impact of cargo ship collision relative to no-load, the shallower penetration depth the striking ship is, the less energy the side structure of the struck ship absorbs. With the striking ship carries more cargo, the penetration depth and the structure energy absorption can reduce accordingly. Therefore, the study of the collision of double-hull oil tankers can not ignore the influence of striking ship which is under the condition of loading.

However, due to the limitations of the research method, the impact of striking ship with loading on ship collision has not been given quantitatively in this paper. In subsequent research, the quantitative relationship between the loading condition of the striking ship(liquid properties, filling ratio and liquid viscosity) and the damage condition of the struck ship(structural deformation, collision depth and structural energy absorption) are worthy of further study.

\section{ACKNOWLEDGEMENTS}

This project is partially supported by Zhejiang Provincial Natural Science Foundation Youth Fund (LQ16E090003, LQ14E090001) and the project of bureau of science and technology of Zhoushan (2015C41009).

\section{REFERENCES}

1. Haris S., Amdahl J.: Analysis of ship-ship collision damage accounting for bow and side deformation interaction. Marine Structures. No 7, Vol. 32, 2013, pp.18-48.

2. Liu B., Soares C.G.: Assessment of the strength of double-hull tanker side structures in minor ship collisions. Engineering Structures. Vol. 120, 2016, pp. 1-12.

3. Prabowo A.R., Dong M.B., Sohn J.M., Zakki A.F., Cao B., Wang Q.: Analysis of structural damage on the struck ship under side collision scenario. Alexandria Engineering Journal. 2017.

4. Liu B.: Analytical method to assess double-hull ship structures subjected to bulbous bow collision. Ocean Engineering. Vol. 142, 2017, pp. 27-38.

5. Liu B., Villavicencio R., Zhang S., Soares C.G.: Assessment of external dynamics and internal mechanics in ship collisions. Ocean Engineering. Vol. 141, 2017, pp. 326-336.
6. Lee S.G., Lee J.S., Lee H.S., Park J.H., Jung T.Y.: Full-scale Ship Collision, Grounding and Sinking Simulation Using Highly Advanced M\&S System of FSI Analysis Technique. Procedia Engineering. Vol. 173, 2017, p.1507-1514.

7. Gagnon R.E., Wang J.: Numerical simulations of a tanker collision with a bergy bit incorporating hydrodynamics, a validated ice model and damage to the vessel. Cold Regions Science and Technology. No 5, Vol. 81, 2012, pp. 26-35.

8. Yu Z., Amdahl J., Storheim M.: A new approach for coupling external dynamics and internal mechanics in ship collisions. Marine Structures. Vol. 45, 2016, pp. 110-132.

9. Zhang A., Suzuki K.: A comparative study of numerical simulations for fluid-structure interaction of liquid-filled tank during ship collision. Ocean Engineering. No 5, Vol. 34, 2007, pp. 645-652.

10. Jie C., Zhang A.M., Yao X.L., Yang S.T.: Influence of liquid cargo in tank on crashworthiness of double-skin side structure. Journal of Ship Mechanics. No 3, Vol. 15, 2011, pp. 259-268.

11. Wu W.F., Yang Y.B., Lu J.S., Deng J.J, Zhu F.X.: Study on liquid cargo sloshing impact on the performance of the double hull oil tanker collision. China Shiprepair. No 6, Vol. 29, 2016, pp.10-14.

12. Tabri K., Matusiak J., Varsta P.: Sloshing interaction in ship collisions-An experimental and numerical study. Ocean Engineering. No 17, Vol. 36, 2009, pp. 1366-1376.

13. Rudan S., Tabri K., Klarić I.: Analysis of sloshing interaction in ship collisions by means of ALE finite element method. In: Proceedings of fifth International Conference on Collision and Grounding of Ships, Espoo, Finland, 2010, pp. 229-234.

14. Sun B., Hu Z., Wang G.: An analytical method for predicting the ship side structure response in raked bow collisions. Marine Structures. Vol. 41, 2015, pp. 288-311.

15. Belytschko T., Lin J.I., Chen-Shyh T.: Explicit algorithms for the nonlinear dynamics of shells. Computer Methods in Applied Mechanics and Engineering. No 2, Vol. 42, 1984, pp. 225-251.

16. Song M., Ma J., Huang Y.: Fluid-structure interaction analysis of ship-ship collisions. Marine Structures. Vol. 55, 2017, pp. 121-136.

17. Rudan S., Volarić D.: Fluid structure interaction analysis of a ship collision. In: Proceedings of the ICCGS 2016, Ulsan, Koreja, 2016. 


\section{CONTACT WITH THE AUTHOR}

Jianwei Zhang, Ph. D.

e-mail: zhangjianwei@zjou.edu.cn tel: 18858397351

School of Port and Transportation Engineering

Zhejiang Ocean University

Zhoushan Zhejiang 316022

China 